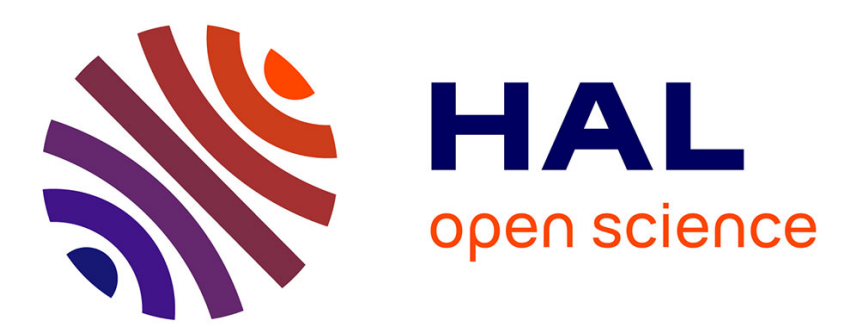

\title{
Nano-Positioning Test platform for Free-Space Six-Port Interferometric Distance Measurements
}

\author{
Nawal Alsaleh, Denis Pomorski, Mohamed Sebbache, Kamel Haddadi, \\ Clément Lenoir
}

\section{- To cite this version:}

Nawal Alsaleh, Denis Pomorski, Mohamed Sebbache, Kamel Haddadi, Clément Lenoir. NanoPositioning Test platform for Free-Space Six-Port Interferometric Distance Measurements. International Conference on Antenna Measurements and Applications, Nov 2021, Antibes Juan-les-Pins, France. hal-03508596

\section{HAL Id: hal-03508596 \\ https://hal.archives-ouvertes.fr/hal-03508596}

Submitted on 3 Jan 2022

HAL is a multi-disciplinary open access archive for the deposit and dissemination of scientific research documents, whether they are published or not. The documents may come from teaching and research institutions in France or abroad, or from public or private research centers.
L'archive ouverte pluridisciplinaire HAL, est destinée au dépôt et à la diffusion de documents scientifiques de niveau recherche, publiés ou non, émanant des établissements d'enseignement et de recherche français ou étrangers, des laboratoires publics ou privés. 


\section{Nano-Positioning Test platform for Free-Space Six-Port Interferometric Distance Measurements}

\author{
Nawal Alsaleh \\ Univ. Lille, CNRS, UMR $9189-$ \\ CRIStAL, $-F-59000$ Lille, France \\ Univ. Lille, CNRS, Centrale Lille, Univ. \\ Polytechnique Hauts-de-France, UMR \\ $8520-I E M N$, Lille, France \\ Univ. Lille, CNRS, USR $3380-$ \\ IRCICA, Lille, France \\ nawal.alsaleh@univ-lille.fr
}

\author{
Denis Pomorski \\ Univ. Lille, CNRS, UMR $9189-$ \\ CRIStAL, -F-59000 Lille, France
denis.pomorski@univ-lille.fr \\ CRIStAL, -F-59000 Lille, France
denis.pomorski@univ-lille.fr
}

Clément Lenoir

\author{
Univ. Lille, CNRS, Centrale Lille, Univ. \\ Polytechnique Hauts-de-France, UMR \\ $8520-I E M N$, Lille, France \\ Univ. Lille, CNRS, USR $3380-$ \\ IRCICA, Lille, France \\ clement.lenoir.etu@univ-lille.fr
}

\author{
Kamel Haddadi \\ Univ. Lille, CNRS, Centrale Lille, Univ. \\ Polytechnique Hauts-de-France, UMR \\ $8520-I E M N$, Lille, France \\ Univ. Lille, CNRS, USR 3380 - \\ IRCICA, Lille, France \\ kamel.haddadi@univ-lille.fr
}

\author{
Mohamed Sebbache \\ Univ. Lille, CNRS, Centrale Lille, Univ. \\ Polytechnique Hauts-de-France, UMR \\ 8520 - IEMN, Lille, France \\ Univ. Lille, CNRS, USR $3380-$ \\ IRCICA, Lille, France \\ mohamed.sebbache@univ-lille.fr
}

\begin{abstract}
Continuous wave (CW) millimeter-wave radars have gained the interest from industry for accurate subwavelength distance measurements. In particular, the six-port radar architecture presents advantages such as high resolution combined with low-power consumption and low-cost implementation in the millimeter-wave regime. In this effort, a new test platform based on fully automated piezo-electric nanopositioning stages that simulates moving targets in $\mathrm{XYZ}$ directions with centimeter range combined with nanometer resolution is described. The test platform is crucial to yield performance metrics in terms of repeatability, sensitivity and accuracy. Preliminary experimental results considering a WR15 six-port CW radar designed and realized for harsh environment operation are presented to validate the approach proposed.
\end{abstract}

Keywords - six-port, millimeter-waves, free-space, radar.

\section{INTRODUCTION}

Precise positioning using millimeter-wave signals has attracted the interest from the research community [1]. In particular, six-port radar technology has been identified as an alternative to the conventional heterodyne architecture [2]. Generally speaking, the six-port is a passive structure based on the interferometric principle featuring two input ports and four output ports [3]. Six-port combines compactness, low energy consumption together with high measurement performance [4]. A variety of six-port systems have been exemplary demonstrated in metallic guide, substrate integrated waveguide (SIW), planar and monolithic forms. Each technology presents own advantages and drawbacks [5][7]. The authors themselves have contributed to the dissemination of the six-port technology in various applications [8]-[19].

The penetration of six-port technology for industrial applications requires dedicated test set-ups to determine intrinsic performance and limitations. In this effort, we use a metallic waveguide six-port interferometer acting as an IQ demodulator operating at $60 \mathrm{GHz}$. The metallic waveguide technology provides isolation between nearby signals and presents immunity to environmental variations. In particular, we introduce a new test platform for accurate distance measurements. This latter is built up with nano-positioning stages from SmarAct $\AA$ and a high performance digital scope for six-port voltages acquisition. In section II, the experimental test platform and principle of operation are described. Experimental results are summarized in Section III.

\section{EXPRIMENTAL TEST PLATFORM}

The block diagram of the proposed distance measurement technique is presented in Fig. 1. The millimeter-wave set-up comprises a frequency synthesizer, waveguide six-port IQ demodulator, low noise amplifier, circulator and horn antenna. The system is completed by a piezo-based nano-positioning stage that holds a metallic target (dimensions $=3.2 \times 4.2 \mathrm{~cm}^{2}$ ).

The six-port IQ demodulator is fed by the frequency synthesizer. The radar function is achieved using a single horn antenna working as transmitter and receiver. To that end, a circulator is included to deliver the received signal by the antenna to the second input port of the six-port IQ demodulator. A low noise amplifier is used to enhance the signal to noise ratio at the signal reception.

The test platform proposed has been fully automated under Labview ${ }^{\circledR}$ environment to set the measurement parameters (RF power, frequency, distance range and step) and to provide detected voltages under different measurement configurations. (Fig. 1). As a demonstration, experiments are considered for $60 \mathrm{GHz}$ near field distance measurement from contact to stand-off set to $5 \mathrm{~mm}$ ( 2 free-space wavelengths). The target is moved along one linear stage in steps of $500 \mathrm{~nm}$ over the full range. The input signal is transmitted to the WR15 horn antenna that radiates the signal towards the target. The metal plate then reflects the signal back to the antenna receiving the signal and transmits it to the second input of the six-port radar. 


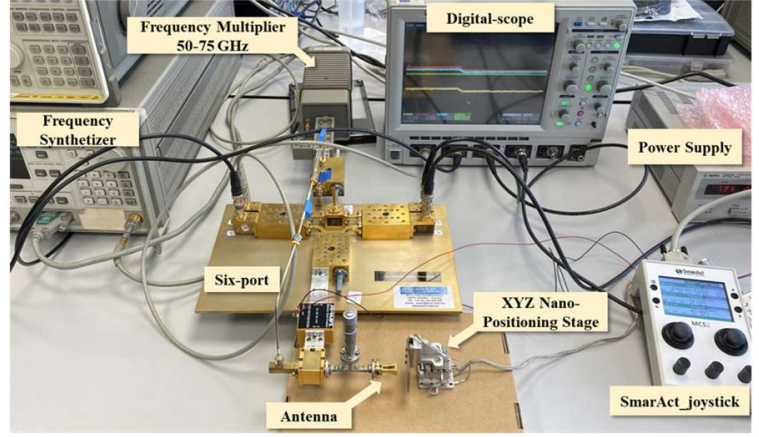

Fig. 1. Proposed test platform for mm-wave free-space distance measurement.

To achieve high measurement accuracy, the linearization (interpolation by a polynomial function) of the six-port detectors to eliminate the distortion of their electrical response is required (Fig. 2). To that end, the detected voltages are measured as a function of the input RF power to apply a linearization algorithm.

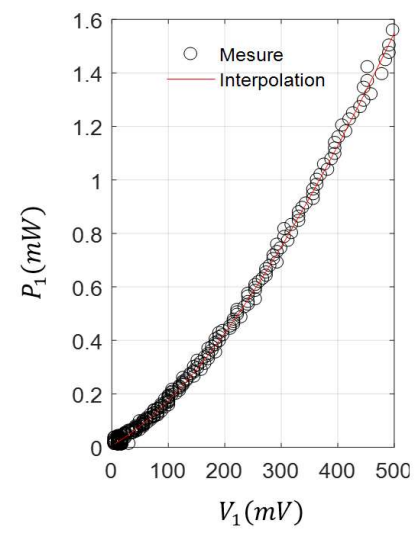

Fig. 2. Input RF power as a function of the measured voltage $V_{1}$ and polynomial interpolation.

From Fig. 2, we notice that the linearity is degraded by distortions. Consequently, the linearization procedure consists to interpolate the measured data using a polynomial function. In this study, a $5^{\text {th }}$ order polynomial is used. As an example, the interpolation model for the power $P_{1}$ is given by:

$$
\begin{aligned}
& P_{1}=-1.1265 \times 10^{-13} V_{1}^{5}+4.8194 \times 10^{-10} V_{1}^{4}- \\
& 6.4135 \times 10^{-8} V_{1}^{3}+6.0750 \times 10^{-5} V_{1}^{2}+1.1082 \times \\
& 10^{-3} V_{1}+8.5 \times 10^{-2}
\end{aligned}
$$

In a second step, guided measurements have been performed to yield intrinsic performance of the six-port IQ demodulator. To that end, a mechanically variable phase- shifter in WR15 technology has been used to control the phase-shift between the LO and RF signals. The theoretical detected output powers $P_{1}(\mathrm{i}=1, . ., 4)$ are given by

$$
\begin{aligned}
& P_{1}=b_{3} \cdot b_{3}^{*}=\frac{1}{4}\left[A_{1}^{2}+A_{2}^{2}+2 A_{1} \sin (\Delta \phi)\right] \\
& P_{2}=b_{4} \cdot b_{4}^{*}=\frac{1}{4}\left[A_{1}^{2}+A_{2}^{2}-2 A_{1} \sin (\Delta \phi)\right] \\
& P_{3}=b_{5} \cdot b_{5}^{*}=\frac{1}{4}\left[A_{1}^{2}+A_{2}^{2}+2 A_{1} A_{2} \cos (\Delta \phi)\right]
\end{aligned}
$$

$$
P_{4}=b_{6} \cdot b_{6}^{*}=\frac{1}{4}\left[A_{1}^{2}+A_{2}^{2}-2 A_{1} A 2 \cos (\Delta \phi)\right]
$$

where $\Delta \phi=\phi_{1}-\phi_{2}$ is the phase shift between the two input LO and RF signals.

The operating frequency is set to $60 \mathrm{GHz}$ and the relative phase-shift $(\Delta \phi)$ is varied from 0 to $360^{\circ}$ with step of $10^{\circ}$. The I and Q components related to the ratio between the LO and RF signals are given by

$$
\begin{aligned}
& I=10^{\frac{A}{20}} \cos (\Delta \phi) \\
& Q=10^{\frac{A}{20}} \sin (\Delta \phi)
\end{aligned}
$$

Fig. 3 shows the detected voltages $V_{1}$ and $V_{3}$ as a function of $\Delta \phi$. The detected voltages present a sinusoidal shape and are in quadrature, in accordance with (2) to (5).

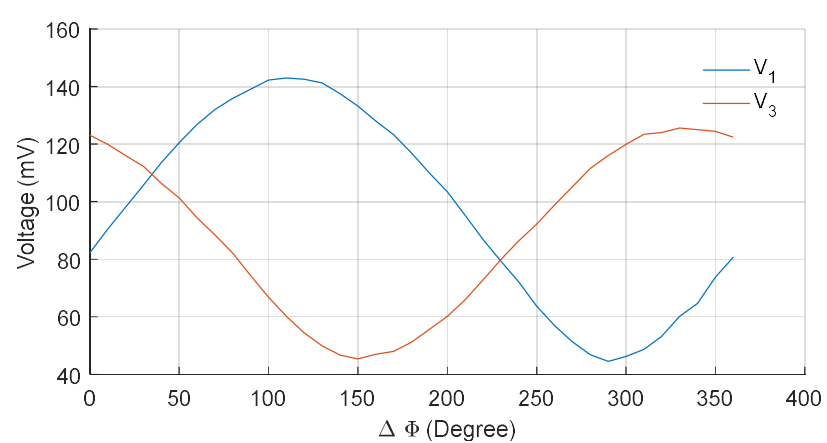

Fig. 3. Detected voltages of the detectors 1 and 3 as function of the relative phase-shift $\Delta \Phi$ between the RF and LO signals- $\mathrm{f}=60 \mathrm{GHz}$.

Finally, free-space application is considering by moving the target from a distance separation $d$ between the antenna aperture and the planar metallic target between 0 (contact) to $5 \mathrm{~mm}$ (two free-space wavelengths at $\mathrm{f}=60 \mathrm{GHz}$ ). The four detected voltages as a function of the distance $d$ are given in Fig. 4. Qualitatively, a good measurement sensitivity to the distance is noticed. The shapes of the curves are not sinusoidal as the target is located in the vicinity of the antenna, in the near-field. In addition, free-space multiple reflections between the antenna aperture and the target yield to signal distortion. Consequently, analytical modeling of the free-space propagation is needed to accurately extract the distance to the target. Fig. 4(c) presents $V_{3}-V_{4}$ as a function of $V_{1}-V_{2}$ that should exhibit graphically a circle centered on 0 for an ideal configuration. An elliptical behavior related to the system imperfections is noticed.

These results are instructive as they demonstrate a good measurement sensitivity with high signal to noise ratio. The proposed experimental set-up does not induce non-systematic errors and other sources of perturbation brought by the operator when the target is moved manually. An analytical model associated to a free-space calibration procedure will be considered in future works to extract the distance from the detected voltages. 


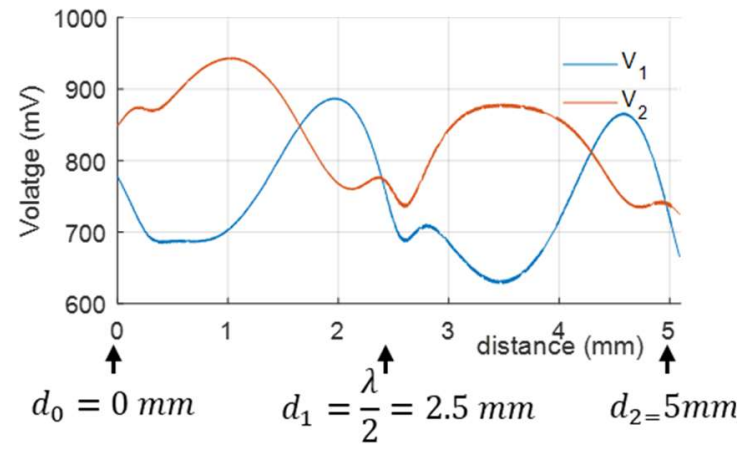

(a)

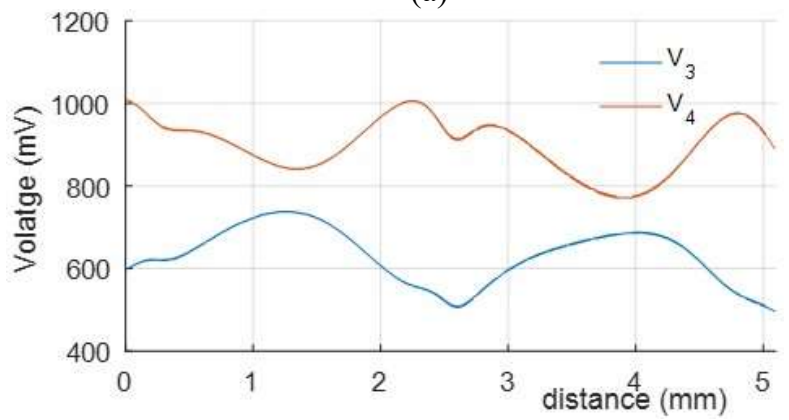

(b)

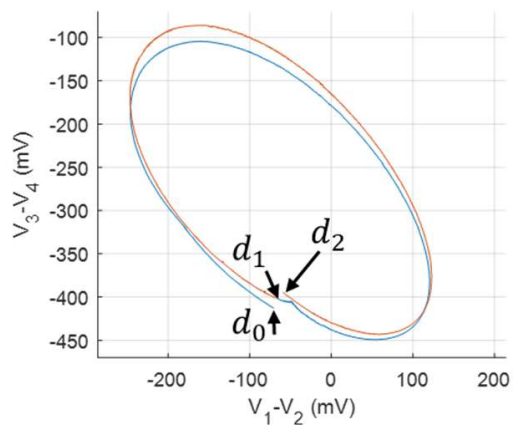

(c)

Fig. 4. Detected voltages of the detectors 1 and 3 as function of the distance separation between the antenna aperture and a metallic target $-\mathrm{f}=60 \mathrm{GHz}$.

\section{CONCLUSION}

A fully automated test platform dedicated to short distance measurements has been proposed. This latter is based on piezo-electric nano-positioning stages that simulates moving targets within centimeter range and nanometer resolution. Preliminary experiments considering a monostatic six-port radar realized in metallic WR15 technology are promising. Future works will include full modelling for the resolution of the inverse problem, i.e. determination of the distance from the detected voltages.

\section{ACKNOWLEDGMENT}

The project is supported by the Nano 2022 Plan in the frame of the common lab IEMN / STMicroelectronics and by the European Metrology Programme for Innovation and Research (EMPIR) Project 18SIB09 Traceability for electrical measurements at millimetre-wave and terahertz frequencies for communications and electronics technologies. The EMPIR Programme is co-financed by the Participating States and from the European Union's Horizon 2020 Research and Innovation Programme.

\section{REFERENCES}

[1] A. Koelpin, G. Vinci, B. Laemmle, D. Kissinger and R. Weigel, "The six-port in modern society," IEEE Microw. Mag., vol. 11, no. 7, pp. 35-43, Dec. 2010

[2] K. Haddadi, M. M. Wang, D. Glay and T. Lasri, "A 60 GHz Six-Port Distance Measurement System With Sub-Millimeter Accuracy," in IEEE Microwave and Wireless Components Letters, vol. 19, no. 10, pp. 644-646, Oct. 2009.

[3] G. Vinci et al., "A Six-Port Radar System for Precise Distance Measurements and Vibration Monitoring in Industrial Environments," Sensors and Measuring Systems 2014; 17. ITG/GMA Symposium, 2014, pp. 1-5.

[4] A. Moscoso-Mártir, et al, "Butler matrix based six-port passive junction," IEEE WiSNet, pp.7-9, Jan. 2014.

[5] S. O. Tatu, A. Serban, M. Helaoui and A. Koelpin, "Multiport technology: the new rise of an old concept," IEEE Microw. Mag., vol. 15, no. 7, pp. 34-44, Nov. 2014

[6] A. Koelpin, F. Lurz, S. Linz, S. Mann, C. Will and S. Lindner, "Sixport based interferometry for precise radar and sensing applications", Sensors, vol. 16, no. 1556, pp. 1-26, Sept. 2016.

[7] K. Haddadi, H. El Aabbaoui, B. Gorisse, D. Glay, N. Rolland and T. Lasri, "A Fully InP Monolithic Integrated Millimeter-Wave Reflectometer," 2006 European Microwave Conference, 2006, pp. 703-706.

[8] K. Haddadi, M. Wang, D. Glay and T. Lasri, "Ultra wide-band fourport reflectometer using only two quadratic detectors," 2008 IEEE MTT-S International Microwave Symposium Digest, 2008, pp. 379382.

[9] K. Haddadi, M. M. Wang, K. Nouri, D. Glay and T. Lasri, "Calibration and Performance of Two New Ultra-Wideband Four-Port-Based Systems," in IEEE Transactions on Microwave Theory and Techniques, vol. 56, no. 12, pp. 3137-3142, Dec. 2008

[10] M. Wang, K. Haddadi, D. Glay and T. Lasri, "Compact near-field microwave microscope based on the multi-port technique," The 40th European Microwave Conference, 2010, pp. 771-774.

[11] K. Haddadi, M. M. Wang, C. Loyez, D. Glay and T. Lasri, "Four-Port Communication Receiver With Digital IQ-Regeneration," in IEEE Microwave and Wireless Components Letters, vol. 20, no. 1, pp. 5860, Jan. 2010 .

[12] K. Haddadi and T. Lasri, "Formulation for Complete and Accurate Calibration of Six-Port Reflectometer," in IEEE Transactions on Microwave Theory and Techniques, vol. 60, no. 3, pp. 574-581, March 2012.

[13] K. Haddadi and T. Lasri, "V-band two-tone continuous wave radar operating in monostatic/bistatic mode," 2012 9th European Radar Conference, 2012, pp. 266-269.

[14] K. Haddadi and C. Loyez, "Millimeter-wave six-port IQ demodulator in $65 \mathrm{~nm}$ SOI CMOS technology," 2016 IEEE International Instrumentation and Measurement Technology Conference Proceedings, 2016, pp. 1-5.

[15] A. E. Fellahi, K. Haddadi, D. Glay and T. Lasri, "Multiport Reflectometer Based on Subtractive Mixing," in IEEE Sensors Journal, vol. 15, no. 9, pp. 4729-4730, Sept. 2015.

[16] C. Loyez, M. Bocquet and K. Haddadi, "Six-Port Technology for 5G Millimeter-Wave Localization Systems," 2018 International Conference on Electromagnetics in Advanced Applications (ICEAA), Cartagena, Colombia, 2018, pp. 272-275.

[17] K. Haddadi, C. Loyez, L. Clavier, D. Pomorski and S. Lallemand, "Sixport reflectometer in WR15 metallic waveguide for free-space sensing applications," 2018 IEEE Topical Conference on Wireless Sensors and Sensor Networks (WiSNet), Anaheim, CA, USA, 2018, pp. 80-83, doi: 10.1109/WISNET.2018.8311570.

[18] K. Haddadi, C. Loyez, L. Clavier, D. Pomorski and S. Lallemand, "Sixport reflectometer in WR15 metallic waveguide for free-space sensing applications," 2018 IEEE Topical Conference on Wireless Sensors and Sensor Networks (WiSNet), Anaheim, CA, USA, 2018, pp. 80-83.

[19] K. Haddadi and T. Lasri, "60-GHz Near-Field Six-Port Microscope Using a Scanning Slit Probe for Subsurface Sensing," in IEEE Sensors Journal, vol. 12, no. 8, pp. 2575-2576, Aug. 2012. 